\title{
Solving the Problem of Video Recording Gaps in Capsule Endoscopy of Overweight Patients
}

Capsule endoscopy [1] is a novel tool for visualizing the small intestine. A passively transported capsule (M2A capsule, Given Imaging, Yoqneam, Israel) transmits two images per second to a sensor array taped onto the patient's abdomen. A small portable recorder collects more than 50000 images, which are downloaded to a computer and then evaluated. Unfortunately, transmission gaps sometimes are observed.

A 36-year-old patient presented with chronic recurrent hypochromic anemia that had persisted for 5 years. Multiple upper and lower endoscopies, push enteroscopy, abdominal computed tomography, and studies of blood and bone had been performed, but the origin of the anemia had remained unclear. The patient was overweight, with a waistline of $144 \mathrm{~cm}$ and a body mass index of 36.8 $(188 \mathrm{~cm}, 130 \mathrm{~kg})$.
Evaluation of the capsule endoscopy revealed a gap of $238 \mathrm{~min}$, beginning after $3 \mathrm{~min} 26 \mathrm{~s}$. The gap included the whole small bowel. The manufacturer checked the recorder, but no dysfunction was found. To obtain a complete examination of the small bowel, capsule endoscopy was repeated. However, in addition to the abdominal sensor array, a second array of sensors was taped to the patient's back at the same level and in the same manner. After 7 hours, the sensor arrays and recorders were removed, and data were downloaded. The ventral recorder again showed a long gap of 177 minutes (Figure 1 ), beginning at $1 \mathrm{~min} 43 \mathrm{~s}$, and only 22966 images were recorded. However, the dorsally mounted system recorded without gaps (Figure 2 ), and the complete passage of $5 \mathrm{~h} 52 \mathrm{~min} 37 \mathrm{~s}$ could be reviewed in 42314 images.
714
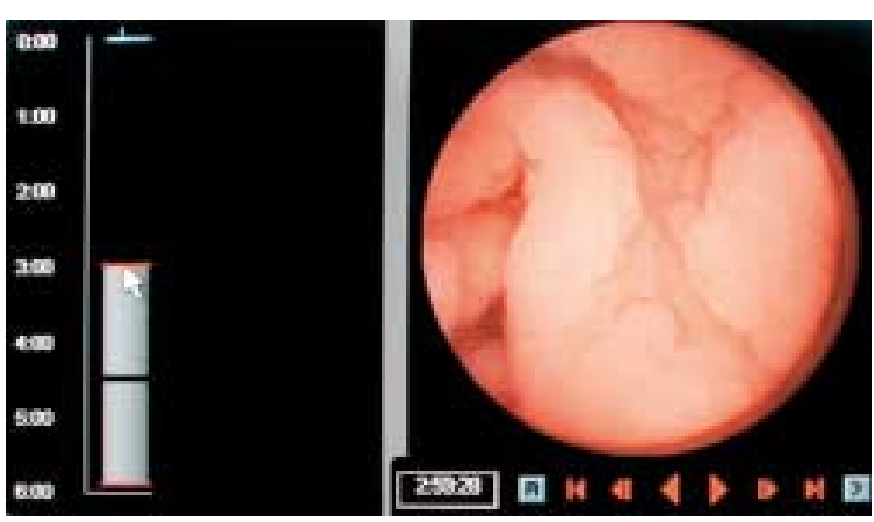

Figure 1 Transmission to the ventral sensor array was incomplete. A gap of 177 min was observed.
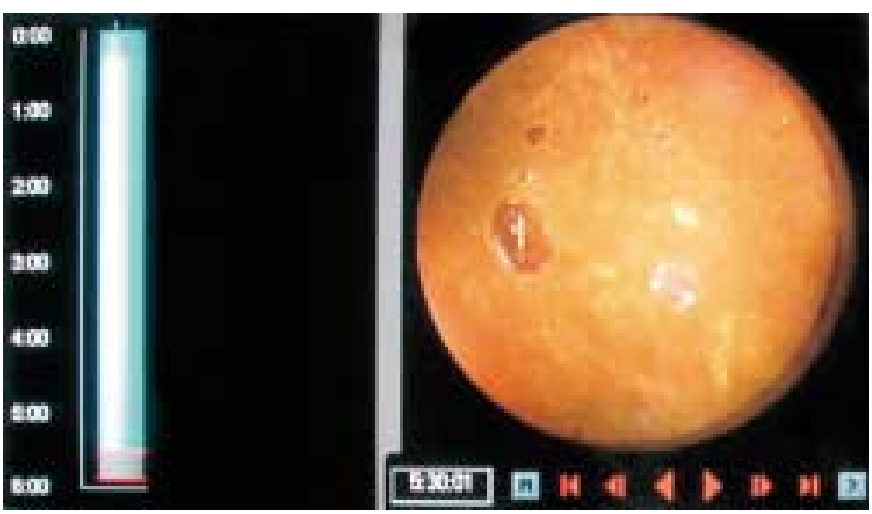

Figure 2 The dorsal sensor array received data over the complete examination period.
Although this is only a single reported case, we would suggest attaching the sensor array to the back of massively overweight patients. There is no disadvantage, apart from discomfort when sitting or lying. This simple trick may avoid video recording gaps and a waste of costly capsules; it may not be needed in the future, as the manufacturer is developing a modified sensor array adjustable to the individual patient's anatomy.

\section{U. Seitz, N. Soehendra}

Dept. of Interdisciplinary Endoscopy, University Hospital, Eppendorf,

Hamburg, Germany

\section{Reference}

${ }^{1}$ Gavriel Iddan G, Meron G, Glukhovsky A et al. Wireless capsule endoscopy. Nature 2000; 405: 417

\section{Corresponding Author}

\section{U. Seitz, M.D}

Dept. of Interdisciplinary Endoscopy University Hospital Eppendorf 20246 Hamburg

Germany

Fax: $\quad+49-40-42803-4420$

E-mail: seitz@uke.uni-hamburg.de 